\title{
Radiologic Response
}

National Cancer Institute

\section{Source}

National Cancer Institute. Radiologic Response. NCI Thesaurus. Code C123627.

An evaluation of the radiologic response of the disease to the therapy. 